\title{
Quality-of-Life after Anterior Skull Base Surgery: A Systematic Review
}

\author{
Matthew A. Kirkman ${ }^{1,2}$ Anouk Borg ${ }^{1} \quad$ Alaa Al-Mousa ${ }^{1}$ Nikolaos Haliasos ${ }^{1}$ David Choi ${ }^{1}$ \\ 1 Victor Horsley Department of Neurosurgery, The National Hospital \\ for Neurology and Neurosurgery, Queen Square, London, United \\ Kingdom \\ 2 Department of Otolaryngology, The Royal National Throat, Nose and \\ Ear Hospital, Gray’s Inn Road, London, United Kingdom \\ Address for correspondence Matthew Kirkman, Bsc, MBBS, MRCS, \\ Victor Horsley Department of Neurosurgery, The National Hospital for \\ Neurology and Neurosurgery, Queen Square, London WC1N 3BG, \\ United Kingdom (e-mail: matthew.kirkman@gmail.com).
}

J Neurol Surg B 2014;75:73-89.

\begin{abstract}
Keywords

- anterior skull base surgery

- endoscopic

- functional outcomes

- quality-of-life

- tumor

Background Improved treatment and survival of patients with skull base tumors has made the assessment of quality-of-life $(\mathrm{QoL})$ in this population increasingly important. This article provides a comprehensive systematic review pertaining to QoL assessment in adults undergoing anterior skull base surgery.

Methods We performed a literature search using the electronic databases of Ovid Medline and Embase. Additional articles were identified through a search using the phrase anterior skull base. Further articles were sought through hand-searching relevant journals and reference lists of identified articles.

Results Our search strategy identified 29 articles for inclusion in our systematic review, with considerable variation between studies in population characteristics, methodological design and quality, follow-up length, and outcome assessment. The most commonly used QoL tools were the Karnofsky Performance Status and the Anterior Skull Base Questionnaire. QoL following anterior skull base surgery appears to improve beyond preoperative levels in the months after surgery. For patients undergoing endoscopic skull base surgery, the gain in QoL appears to be greater and may manifest earlier, with no clear long-term deleterious effect on sinonasal outcomes compared with open surgery.

Conclusions QoL after anterior skull base surgery in adults appears to improve within several months of surgery, but earlier and to a larger extent if the endoscopic approach is used. Given the relative paucity and heterogeneity of anterior skull base tumors, largescale prospective multicentre studies utilizing valid and reliable multidimensional QoL tools are required. This may result in improved patient care, by understanding patients' needs better and facilitating the provision of reliable outcome data for clinical trials.
\end{abstract}

\section{Introduction}

Research in skull base tumors has traditionally focused on clinical end points such as mortality rates, complications, extent of surgical resection, response to radiation therapy, and cure. Although these are undoubtedly important markers of clinical outcome, they fail to account for the patient's quality-of-life (QoL) as a tangible and significant outcome

received

June 4, 2013

accepted after revision

September 18, 2013

published online

December 11, 2013

measure. Although no standardized definition of QoL exists, it is widely considered to be a multidimensional construct that encompasses a patient's perception of overall well-being at a specific point in time. ${ }^{1}$ It is not the same as symptom assessment because the same symptom in two individuals may have significantly different perceived impacts. ${ }^{2}$

QoL as a concept is especially important in those with skull base tumors because the surgery is often complicated, extensive,

(c) 2014 Georg Thieme Verlag KG Stuttgart · New York
DOI http://dx.doi.org/ 10.1055/s-0033-1359303. ISSN 2193-6331. 
and associated with significant morbidity. Although the seminal paper by Karnofsky and Burchenal introducing a standardized measure of functional status was published $>60$ years ago, ${ }^{3}$ only in the past decade have standardized QoL assessment tools become adopted by the skull base community. Several such tools are now available. Some are generic and others specific to the site or type of pathology. Some rely on a clinician's assessment of the patient; others are patient-reported outcome measures (PROMs). Some assess one aspect of the patient's QoL (so-called unidimensional), such as physical function or emotional wellbeing, and others are multidimensional.

More recently, focus has been on the use of multidimensional and site-specific or disease-specific PROMs. The most notable example in skull base surgery is the Anterior Skull Base Questionnaire (ASBQ). ${ }^{4,5}$ The importance of using PROMs rather than clinician-reported outcome measures is illustrated by a study using the ASBQ in which poor correlation was found between a patient's self-rating and the surgeon's perception of that patient's QoL. ${ }^{6}$ As such, PROMs represent the gold standard measure of QoL, providing validated and objective data across multiple domains.

This article systematically reviews the literature pertaining to QoL assessment in adults undergoing anterior skull base surgery.

\section{Methods}

\section{Data Sources and Search Strategy}

We prespecified the methods used in this systematic review and present them in accordance with Preferred Reporting Items for Systematic Reviews and Meta-Analyses guidelines. ${ }^{7}$ To maximize the number of papers identified, two separate search strategies were used. In the first, a literature search was performed using the electronic databases of Ovid Medline (1946 to May, Week 2, 2013) and Embase (1974 to Week 20, 2013). A search strategy was created using the terms highlighted in - Table 1, which included Medical Subject (MeSH) Headings. Results were then reviewed to exclude manuscripts not published in the English language, and duplicates were also removed (-Fig. 1). The abstracts of all remaining articles were reviewed to exclude irrelevant studies. The full texts of the remaining articles were then reviewed, creating a final group of articles from this search strategy for inclusion in our systematic review.

In the second search strategy, we performed a search with the phrase anterior skull base to remain deliberately broad. Four authors (MAK, AB, AA, and NH) each reviewed a quarter of the search results (title and abstract) for inclusion in our systematic review. Further articles were sought through hand-searching relevant journals and reference lists of the identified articles.

\section{Study Selection}

We included original articles that quantitatively reported QoL in adult patients ( $>18$ years of age) undergoing skull base surgery for tumors via an anterior approach. Tumors of the anterior skull base managed using a purely lateral surgical approach were excluded. Articles describing QoL in surgery
Table 1 Primary search strategy to identify relevant studies using Ovid Medline and Embase

\begin{tabular}{|l|l|l|}
\hline Number & Search terms & Number of articles \\
\hline 1 & 'functional outcom*'.mp & 40,884 \\
\hline 2 & $\begin{array}{l}\text { 'skull base'.mp OR } \\
\text { MeSH: Skull Base/ }\end{array}$ & 22,066 \\
\hline 3 & $\begin{array}{l}\text { 'quality-of-life'.mp } \\
\text { OR QOL.mp OR } \\
\text { HRQOL.mp OR } \\
\text { MeSH: "Quality-of-Life”/ }\end{array}$ & 441,366 \\
\hline 4 & 1 or 3 & 479,047 \\
\hline 5 & 2 and 4 & 486 \\
\hline
\end{tabular}

for nasopharyngeal tumors that did not extend into the skull base were also excluded. Manuscripts that included a combination of tumors managed through anterior approaches and others through nonanterior approaches were not excluded.

\section{Data Extraction and Quality Assessment}

Data from studies meeting our inclusion and exclusion criteria were extracted using a standardized data extraction tool and critically appraised.

\section{Results}

\section{Selected Articles}

Our initial search strategy (-Table 1) identified 486 papers. After excluding those not published in English and duplicates identified using Ovid, 275 articles remained and underwent title and abstract screening (-Fig. 1), which, after further review, were reduced to 38 articles for full-text review. Following full-text review, 16 articles were excluded, leaving 22 articles for inclusion in this systematic review. An additional seven articles were found following the search previously described, and through hand-searching relevant journals and reference lists. Twenty-nine articles were therefore identified for inclusion in our systematic review (Appendix 1).

\section{Characteristics of Included Studies and Study Settings} Most of the studies were performed either in the United States $(n=10 ; 34 \%)$, Israel $(n=5 ; 17 \%)$, or Germany $(n=5)$. Most studies were published in the past 15 years, with just over half ( $n=15$ ) of all studies published in the past 5 years (2009-2013). Most studies incorporated data collection within the past 2 decades, although three (10\%) manuscripts did not describe the time period of the study.

Eleven studies (38\%) focused on one or two specific skull base tumor types, one (3\%) did not specify pathology included in the study, and the remainder $(n=17 ; 59 \%)$ included a heterogeneous population of skull base tumors. Eighteen articles (62\%) focused on tumors of the anterior cranial fossa only, one (3\%) study did not describe the specific location of the skull base tumors studied, and the remainder (34\%) incorporated tumors in two or more anatomical regions (anterior, middle, lateral and/or posterior cranial fossa). A 


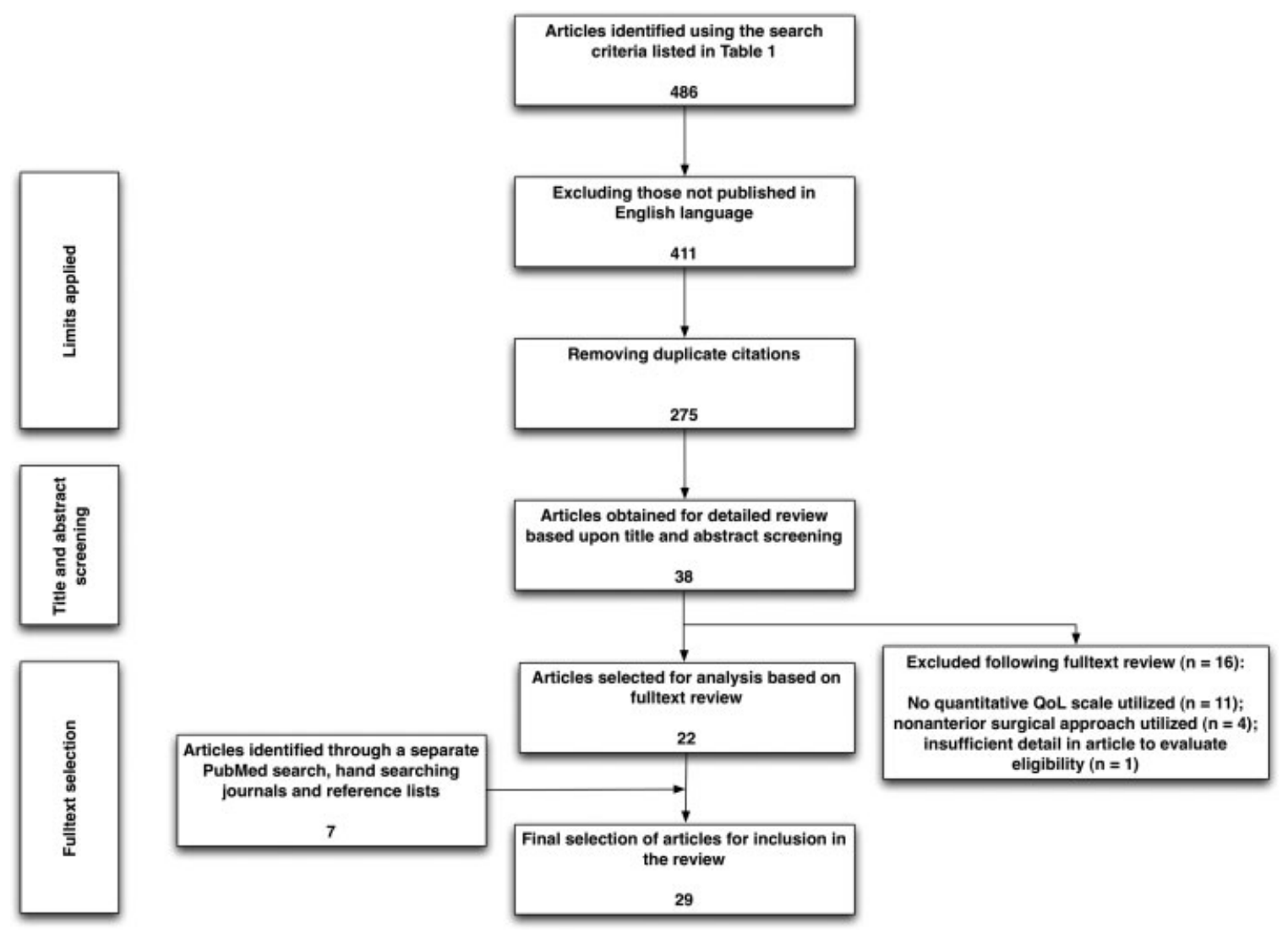

Fig. 1 Flow diagram of our study selection process. QoL, quality-of-life.

variety of surgical approaches were used, both open and endoscopic (Appendix 1).

The most common QoL measure used was the Karnofsky Performance Status (KPS) $(n=13 ; 45 \%)$, followed by the ASBQ $(n=8 ; 28 \%)$. The remaining QoL measures used are shown in -Table 2 and described later.

\section{Study Quality and Level of Evidence}

There were no randomized controlled trials identified. Ten studies (34\%) were prospective, one (3\%) had both prospective and retrospective elements, and the remaining studies (62\%) were retrospective. Only two studies (7\%) had control groups.

\section{Data Synthesis}

Study findings are reported below according to the QoL scale used ( $\mathbf{-}$ Table $\mathbf{2}$ ), broadly divided into two categories depending on whether the assessment tool used was a global or sitespecific (for anterior skull base surgery) QoL measure. Given the wide variations in study design, reporting quality, and outcome measures, meta-analysis was not possible.

\section{Global Quality-of-Life Measures}

\section{Karnofsky Performance Status}

The KPS is a rating scale of functional status determined by health care providers, intended to be a proxy for QoL. ${ }^{3}$ Scores range from 0 to 100 , with a higher score indicating better functional status. Although valuable as a gross estimate of functional status, it only measures one facet of the broader concept of QoL. Our search strategy identified 13 studies incorporating KPS data (-Table $\mathbf{3}$ ).

Most studies incorporating KPS data compared pre- and postoperative scores. In a variety of skull base pathologies, ${ }^{8}$ clival and cranial base chordomas, ${ }^{9,10}$ anterior clinoid process meningiomas, ${ }^{11}$ and skull base meningiomas of various locations, ${ }^{12}$ average KPS scores were shown to increase following surgery (-Table 3 ). However, these studies incorporate a variety of pathologies, anatomical locations, surgical approaches, and lengths of follow-up. For example, in one study of skull base meningiomas, only $3 \%$ of subjects had tumors in the anterior cranial fossa. ${ }^{13}$ This is important because physical symptoms following skull base surgery depend on tumor location as well as surgical approach. ${ }^{14}$ Some studies did not specify the surgical approach used, ${ }^{13,15-17}$ assessed KPS only preoperatively ${ }^{15}$ or postoperatively, ${ }^{18}$ assessed KPS between subjects at variable time points following surgery, ${ }^{16}$ or did not specify when the KPS assessment was undertaken. ${ }^{19,20}$ One study also failed to report specific mean KPS scores. ${ }^{21}$

It is widely believed that improvements in surgical techniques have contributed to improved patient outcomes following skull base surgery in recent years. Studies have suggested that more recent surgery appears to result in improved postoperative KPS scores for patients with clival and cranial base chordomas, ${ }^{10}$ and skull base meningiomas ${ }^{12}$ compared with those undergoing surgery in earlier periods. 
QoL after Anterior Skull Base Surgery Kirkman et al.

Table 2 Quality-of-life instruments commonly used in patients undergoing anterior skull base surgery

\begin{tabular}{|c|c|c|c|c|}
\hline Instrument & $\begin{array}{l}\text { Site specific } \\
\text { (for skull base surgery)? }\end{array}$ & Multidimensional? & $\begin{array}{l}\text { Intended for patient or } \\
\text { clinician completion? }\end{array}$ & Domains \\
\hline \multicolumn{5}{|l|}{$\begin{array}{l}\text { Global quality-of-life } \\
\text { measures }\end{array}$} \\
\hline $\begin{array}{l}\text { Glasgow Outcome } \\
\text { Score (GOS) }\end{array}$ & No & No & Clinician & $\mathrm{N} / \mathrm{A}$ \\
\hline $\begin{array}{l}\text { Health Utilities Index } \\
\text { (HUI) Mark } 2 \text { (HUI2) }\end{array}$ & No & Yes & Either & $\begin{array}{l}\text { Sensation, mobility, } \\
\text { emotion, cognitive, } \\
\text { self-care, pain, and } \\
\text { fertility ( } 1 \text { item each). }\end{array}$ \\
\hline $\begin{array}{l}\text { Karnofsky } \\
\text { Performance Status } \\
\text { (KPS) }\end{array}$ & No & No & Clinician & $\mathrm{N} / \mathrm{A}$ \\
\hline Short Form-36 & No & Yes & Either & $\begin{array}{l}\text { Physical function } \\
\text { (10 items), role } \\
\text { physical ( } 4 \text { items), } \\
\text { bodily pain ( } 2 \text { items), } \\
\text { general health } \\
\text { ( } 5 \text { items), vitality } \\
\text { ( } 4 \text { items), social } \\
\text { function ( } 2 \text { items), role } \\
\text { emotional ( } 3 \text { items), } \\
\text { mental health ( } 5 \\
\text { items), and } \\
\text { perceived change in } \\
\text { health ( } 1 \text { item). }\end{array}$ \\
\hline Short Form-12 & No & Yes & Either & $\begin{array}{l}\text { General health } \\
\text { ( } 1 \text { item), physical } \\
\text { function ( } 2 \text { items), role } \\
\text { physical ( } 2 \text { items), } \\
\text { bodily pain ( } 1 \text { item), } \\
\text { role emotional } \\
\text { ( } 3 \text { items), mental } \\
\text { health ( } 1 \text { item), vitality } \\
\text { ( } 1 \text { item), social } \\
\text { function ( } 1 \text { item). }\end{array}$ \\
\hline $\begin{array}{l}\text { University of } \\
\text { Washington } \\
\text { Quality-of-Life scale }\end{array}$ & No & Yes & Patient & $\begin{array}{l}\text { Pain, appearance, } \\
\text { activity, recreation, } \\
\text { swallowing, chewing, } \\
\text { speech, shoulder pain, } \\
\text { taste, saliva, mood, } \\
\text { and anxiety (1 item } \\
\text { each)(in addition to } \\
\text { three general } \\
\text { questions). }\end{array}$ \\
\hline Quality-of-Life Index & No & Yes & Patient & $\begin{array}{l}\text { Job, self-assessment, } \\
\text { leisure, eating, } \\
\text { sleeping, friendship, } \\
\text { money, family, part- } \\
\text { nership, health, and } \\
\text { overall QoL (1 item } \\
\text { each). }\end{array}$ \\
\hline $\begin{array}{l}\text { Functional } \\
\text { Assessment of } \\
\text { Cancer-Head and } \\
\text { Neck (FACT-H\&N) }\end{array}$ & No & Yes & Patient & $\begin{array}{l}\text { Physical well-being } \\
\text { ( } 7 \text { items), social/family } \\
\text { well-being ( } 7 \text { items), } \\
\text { emotional well-being } \\
\text { ( } 6 \text { items), functional } \\
\text { well-being ( } 7 \text { items), } \\
\text { additional concerns } \\
\text { relevant to head and } \\
\text { neck ( } 12 \text { items). }\end{array}$ \\
\hline
\end{tabular}


Table 2 (Continued)

\begin{tabular}{|c|c|c|c|c|}
\hline Instrument & $\begin{array}{l}\text { Site specific } \\
\text { (for skull base surgery)? }\end{array}$ & Multidimensional? & $\begin{array}{l}\text { Intended for patient or } \\
\text { clinician completion? }\end{array}$ & Domains \\
\hline $\begin{array}{l}\text { Centre for } \\
\text { Epidemiologic } \\
\text { Studies Depression } \\
\text { Scale (CES-D) }\end{array}$ & No & No & Patient & $\mathrm{N} / \mathrm{A}$ \\
\hline $\begin{array}{l}\text { Atkinson Life } \\
\text { Happiness Rating } \\
\text { (ALHR) }\end{array}$ & No & No & Patient & $\mathrm{N} / \mathrm{A}$ \\
\hline \multicolumn{5}{|l|}{$\begin{array}{l}\text { Site-specific quality-of- } \\
\text { life measures }\end{array}$} \\
\hline $\begin{array}{l}\text { Anterior skull base } \\
\text { survey }\end{array}$ & Yes & Yes & Patient & $\begin{array}{l}\text { Role of performance } \\
\text { ( } 6 \text { items), physical } \\
\text { function ( } 7 \text { items), } \\
\text { vitality ( } 7 \text { items), pain } \\
\text { ( } 3 \text { items), specific } \\
\text { symptoms ( } 7 \text { items), } \\
\text { and impact on } \\
\text { emotions ( } 5 \text { items). }\end{array}$ \\
\hline $\begin{array}{l}\text { Anterior Skull Base } \\
\text { (ASK) Nasal } \\
\text { Inventory-9 }\end{array}$ & Yes & No & Patient & $\mathrm{N} / \mathrm{A}$ \\
\hline $\begin{array}{l}\text { Anterior Skull Base } \\
\text { (ASK) Nasal } \\
\text { Inventory-12 }\end{array}$ & Yes & No & Patient & $\mathrm{N} / \mathrm{A}$ \\
\hline $\begin{array}{l}\text { Sinonasal Outcome } \\
\text { (SNOT)-22 }\end{array}$ & Yes & Yes & Patient & $\mathrm{N} / \mathrm{A}$ \\
\hline $\begin{array}{l}\text { Rhinosinusitis } \\
\text { Outcome Measure } \\
\text { (RSOM)-31 }\end{array}$ & Yes & Yes & Patient & $\begin{array}{l}\text { Nasal QoL } \\
\text { (6 questions), eye QoL } \\
\text { (2 questions), sleep } \\
\text { QoL (4 questions), ear } \\
\text { QoL (5 questions), } \\
\text { general questions } \\
\text { (7 questions), practical } \\
\text { issues (4 questions), } \\
\text { and emotional } \\
\text { well-being } \\
\text { (3 questions). }\end{array}$ \\
\hline $\begin{array}{l}\text { Midface Dysfunction } \\
\text { Scale (MDS) }\end{array}$ & Yes & No & Patient & $\mathrm{N} / \mathrm{A}$ \\
\hline
\end{tabular}

Better 5-year survival rates and markedly fewer overall complications were observed in patients undergoing surgery from 2000 to 2011 compared with 1988 to $1999 .^{10}$ In one study, early surgery (performed between 1985 and 1994) was actually associated with a decrease in KPS. ${ }^{12}$ In other studies, of skull base meningiomas in varying locations, KPS scores preoperatively and at last follow-up were lower but not significantly so. ${ }^{13,16}$

Some studies have attempted to find variables associated with a worse KPS score. In a study of skull base meningiomas, female gender, higher histologic grade and p53-positive rate were associated with an unfavorable KPS, but radiation therapy, degree of resection, tumor size, tumor location, age of the patient, presence of calcification or a high T2weighted image were not. ${ }^{16}$ In another study of skull base meningiomas, subtotal resection was associated with a significant decrease in KPS only in those $<70$ years of age. ${ }^{13} \mathrm{~A}$ decline in KPS has been correlated with the development of recurrence or progression in subjects with olfactory groove meningiomas. ${ }^{21}$

\section{Short Form-12 and -36}

The Short Form is a well-known generic QoL measure that has been used in many different conditions and comes in several forms. One study used the SF- $36^{22}$ and one study the SF- $12 .^{23}$ Both the SF-36 and SF-12 cover eight domains, with 36 and 12 items, respectively, grouped into "mental" and "physical" subscores. Scores are scaled to range from 0 (worst) to 100 (best). In a study of 14 patients with a variety of skull base tumors who underwent extended transbasal surgery, SF-36 


\begin{tabular}{|c|c|c|c|c|c|c|}
\hline 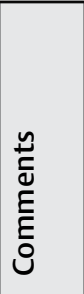 & 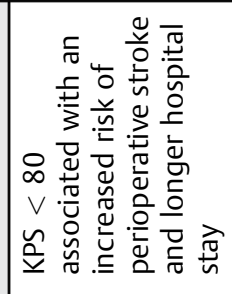 & 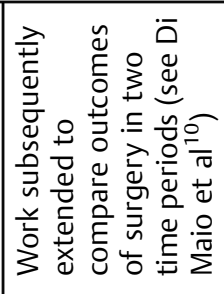 & 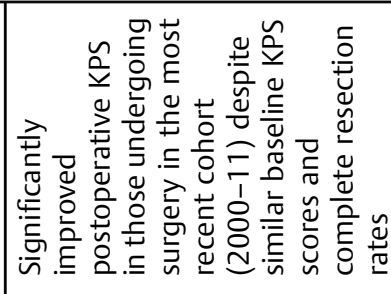 & & 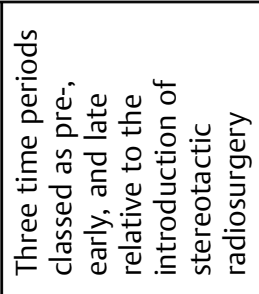 & 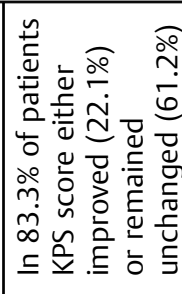 \\
\hline 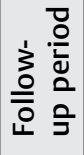 & $\stackrel{\circ}{E}$ & \begin{tabular}{|l}
$\circ$ \\
Ė \\
ğ
\end{tabular} & $\begin{array}{l}\stackrel{o}{E} \\
\text { m } \\
\infty \\
\infty \\
m\end{array}$ & $\vec{~}$ & $\begin{array}{l}\stackrel{\circ}{E} \\
\text { m. } \\
\text { ผn }\end{array}$ & 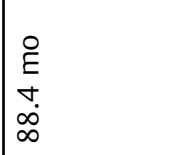 \\
\hline 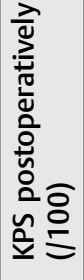 & 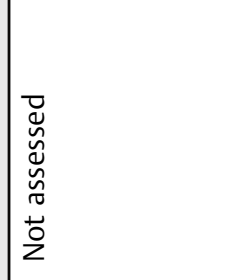 & 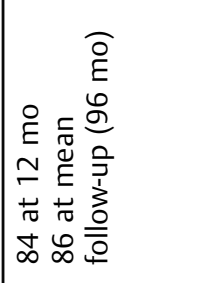 & 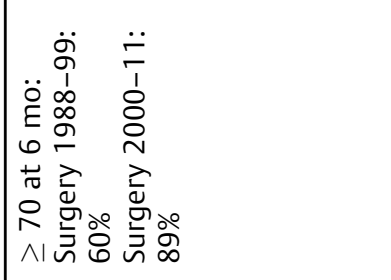 & 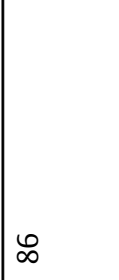 & 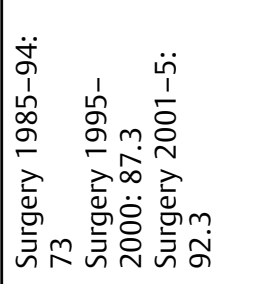 & $\begin{array}{l}\sim \\
\infty \\
\infty \\
\infty\end{array}$ \\
\hline 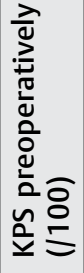 & 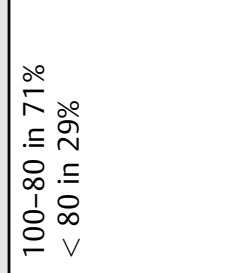 & 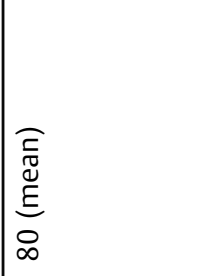 & 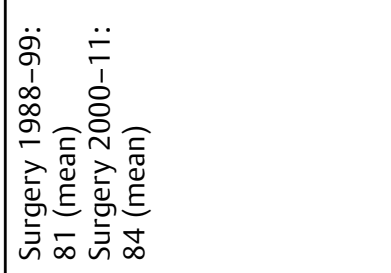 & $\infty$ & 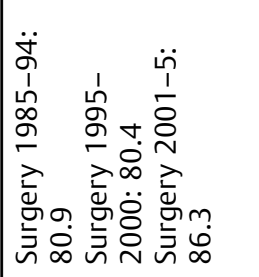 & $\begin{array}{l}0 \\
\dot{8}\end{array}$ \\
\hline 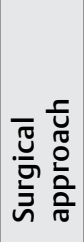 & 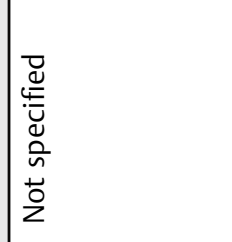 & 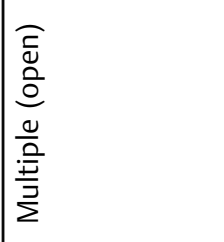 & 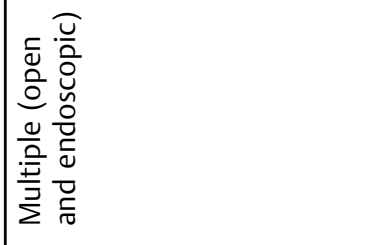 & 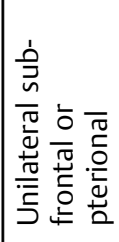 & 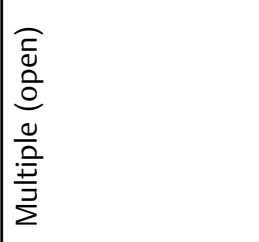 & 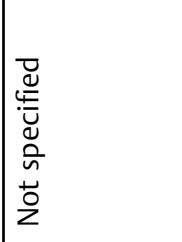 \\
\hline 号 & 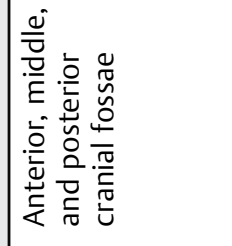 & 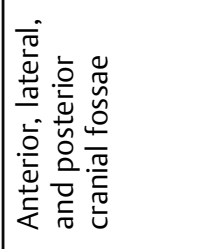 & 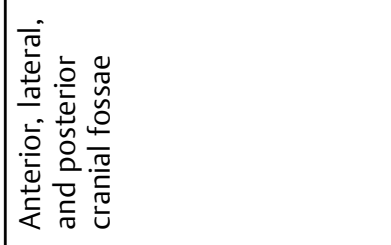 & 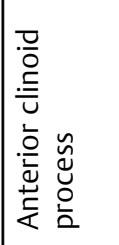 & 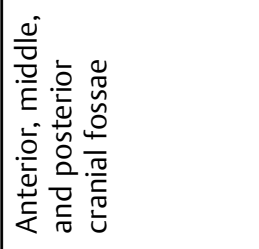 & 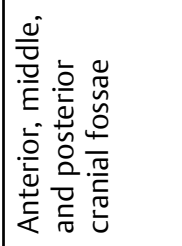 \\
\hline 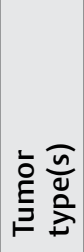 & $\frac{\frac{0}{2}}{\frac{2}{3}}$ & 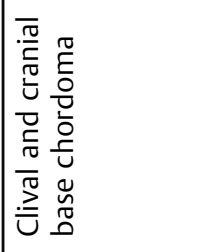 & 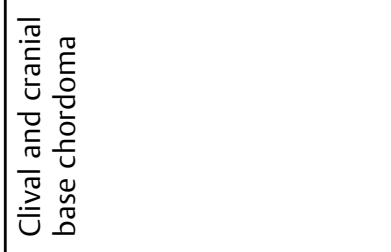 & 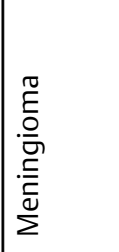 & 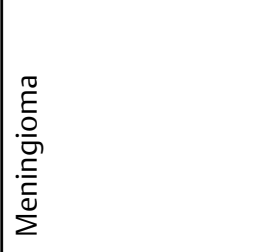 & 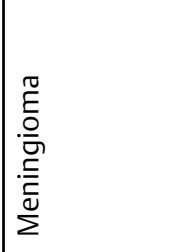 \\
\hline$z$ & I & $\stackrel{\nabla}{N}$ & 느 & $\stackrel{一}{\circ}$ & $\bar{\sigma}$ & $\stackrel{\infty}{\sim}$ \\
\hline $\begin{array}{l}\text { ते } \\
\text { जे }\end{array}$ & 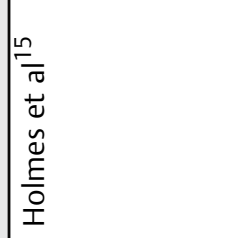 & 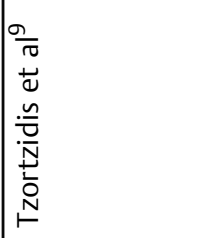 & 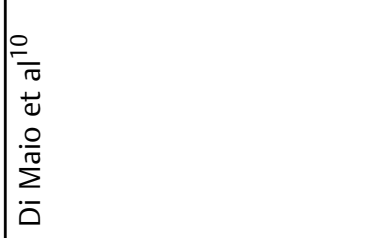 & 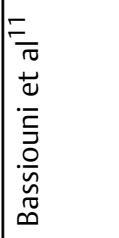 & 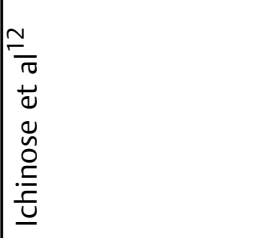 & $\begin{array}{l}\frac{0}{\pi} \\
\frac{0}{0} \\
\tilde{U} \\
\tilde{0} \\
\frac{0}{0}\end{array}$ \\
\hline
\end{tabular}




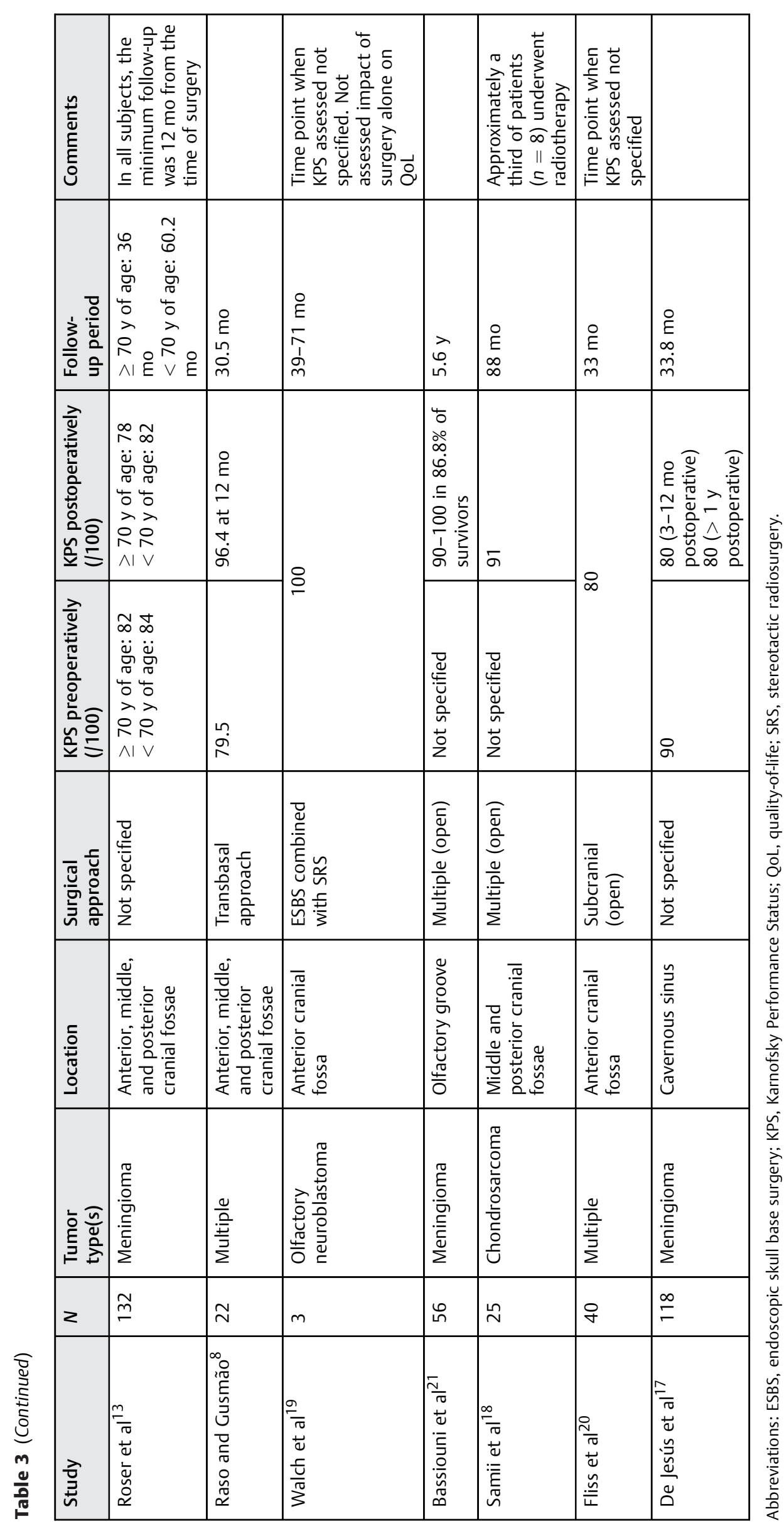


scores at a minimum of 1 year following surgery were improved across all domains in half of the patients. ${ }^{22}$ In the remainder, scores did not improve, but physical health, vitality, and perceived health were actually worse in one, two, and two patients, respectively.

The SF-12 was used in a study of 11 patients undergoing endoscopic skull base surgery for a range of benign and malignant skull base tumors. ${ }^{23}$ With 12 -month follow-up, the authors found a nonsignificant increase in the physical and mental subscores compared with preoperative scores, with greater improvement in the mental subscores (7.5 versus 4.1 points).

\section{The University of Washington Quality-of-Life Scale}

The University of Washington Quality-of-Life (UW-QOL) scale was developed specifically for self-rating of QoL in patients with head and neck cancers. ${ }^{24,25}$ The latest version (version 4 ) includes 12 single-question domains, each having between three and six response options scaled evenly from 0 (worst) to 100 (best), and three global questions (scored from 0 to 5 ). It has been used once in patients undergoing anterior skull base surgery, but it does not account for some symptoms specific to anterior skull base tumors, such as those relating to vision and olfaction.

A study of 18 patients reporting UW-QOL scale scores at varying time points after treatment (and 94\% of patients underwent radiotherapy) found scores to be significantly lower in those with anterior skull base tumors compared with lateral skull base tumors (916.5 versus 1060 of 1200). ${ }^{26}$ Various open surgical approaches were used, and one patient underwent endoscopic surgery. The domains of mood, activity, recreation, taste, and anxiety were worse in the anterior group (the latter two significantly so), and recurrence did not appear to influence scores. More than a third of patients were found to be at risk of mental distress and psychiatric morbidity in this cohort.

\section{Glasgow Outcome Score}

The Glasgow Outcome Score (GOS) is a well-known scale used to classify patients with brain injury, ranging from 1 (death) to 5 (good recovery). It is considered easy to use but does not provide high-quality information that may be interpreted in a meaningful way. ${ }^{27}$ The GOS does not account for the potentially profound effects of skull base surgery on psychological well-being and socioeconomic status and, as a global measure, it does not incorporate assessment of symptoms considered important for patients specifically undergoing skull base surgery.

In one study including 18 patients with extended transbasal operations for a variety of skull base tumors, 14 patients had made a good recovery at a minimum of 1-year follow-up, and 2 patients had died. ${ }^{22}$ However, baseline GOS data were not reported.

\section{Health Utilities Index Mark 2}

The Health Utilities Index (HUI)-2 is considered a sensitive and versatile multidimensional QoL measure, with 7 items over 7 domains generating a score between 0 (death) and 1 (full health). ${ }^{23}$ It is not site specific, however, and thus does not detect all symptoms important for skull base surgery patients. One study used HUI-2 in 11 patients undergoing endoscopic skull base surgery for benign and malignant skull base tumors, finding mean baseline HUI-2 scores to be significantly worse in those with malignant tumors $(0.63)$ compared with benign tumors (0.87). ${ }^{23}$ This difference was lost at follow-up of 3, 6, and 12 months, but a nonsignificant lower mean score in the malignant group persisted $(0.82$ versus 0.93). Scores were stable or improved in most patients (91\%) over time, with an overall gain of 0.13 points for the cohort, but this increase was nonsignificant.

\section{Quality-of-Life Index}

Based on a modified version of the QoL scale of Blau, ${ }^{28}$ Woertgen and colleagues assessed outcome in 12 patients undergoing surgery for anterior skull base tumors through various approaches. ${ }^{29}$ The 11 -item self-reported questionnaire includes a question in each of 10 domains and an overall QoL rating, with scores for each ranging from 0 (worst) to 100 (best outcome). With a mean follow-up of 40 months, the authors found that only $45 \%$ of subjects were able to return to their previous occupation, and mean Quality-of-Life Index score was 42, with the job item and family item having the lowest and highest values, respectively. All patients underwent radiotherapy. Only half of the 12 patients actually completed the survey themselves. The other six responses were from relatives of patients who had died. Although in another survey, caregivers were able to provide a good assessment of a patient's self-reported QoL, ${ }^{6}$ this may not be true in the context of this specific questionnaire. Furthermore, no preoperative data was provided for comparison.

\section{Functional Assessment of Cancer-Head and Neck}

The Functional Assessment of Cancer-Head and Neck (FACT$\mathrm{H} \& \mathrm{~N}$ ) is a 39-item QoL self-reporting questionnaire designed for patients with head and neck cancer, with each item scoring between 0 (not at all) to 4 (very much). It consists of 27 general items (FACT-G) over four domains, and 12 items for head and neck symptom assessment (H\&N-G), but it does not address some issues relevant to anterior skull base surgery.

One study of 27 patients undergoing cranial, transfacial, and craniofacial approaches to a variety of benign and malignant skull base tumors used the FACT-H\&N questionnaire. ${ }^{30}$ The median overall FACT-H\&N score postoperatively was 118 , with use of radiotherapy and presence of recurrence at last follow-up (minimum 6 months; median 5 years) were both associated with a significant reduction in the H\&N-G subscale. No preoperative data were presented.

\section{Centre for Epidemiologic Studies Depression Scale} The Center for Epidemiologic Studies Depression Scale (CES-D) is a 20 item self-reported assessment of depressive symptoms that has been used widely in cancer patients. It was used in the same study as that using FACT-H\&N, ${ }^{30}$ with an additional question on suicidal ideation. The median CES-D score was 
17 (range: 9-46), higher (better) than average for most studies of cancer patients.

\section{Atkinson Life Happiness Rating}

The Atkinson Life Happiness Rating (ALHR) is a single-item QoL measure used in the self-reported assessment of overall well-being, using a 11-point scale ranging from 1 (very unhappy) to 11 (very happy). It has been used in several studies of patients affected by chronic or life-threatening conditions. ${ }^{30}$ Also used in the same study as the FACT-H\&N and CES-D questionnaires, ${ }^{30}$ the median response to the ALHR was 9, indicating that most patients were very satisfied with their lives. No significant associations were found between gender, marital status, malignant histopathology, surgical approach, complication rate, or length of hospital stay and scores on the FACT-H\&N, ALHR, or CES-D.

\section{Site-Specific Quality-of-Life Measures}

\section{Anterior Skull Base Questionnaire}

The most widely utilized site-specific tool for QoL assessment following anterior skull base surgery is the ASBQ. First published in 2003, it has been validated for use in patients undergoing anterior skull base tumor surgery. ${ }^{4,5}$ It consists of 35 items covering six domains, with scores for each item ranging from 1 (poor) to 5 (excellent), and thus total scores range from 35 to 175 (higher scores are better). The questions cover aspects of taste, smell, appearance, nasal function, and visual function, in addition to more general questions on mood, energy levels, and pain. Questions are phrased to detect changes from preoperative levels. The ASBQ has been found to predict the postoperative QoL of different groups of patients undergoing skull base tumor surgery even prior to surgery. ${ }^{20}$ The lack of a significant correlation between general QoL questions and any of the specific domains of the ASBQ suggests that either general questions cannot reliably detect a specific change in a disease process, or, alternatively, specific questions may be too focused to detect changes in overall QoL. ${ }^{5}$

We identified eight studies reporting ASBQ scores in a variety of tumors resected by through open and endoscopic approaches ( - Table 4 ). The process of surgery itself appears to have an impact on the patient's financial status and emotional state the most. ${ }^{4}$ Most studies have found QoL to vary significantly over the course of time following surgery, although there are exceptions. ${ }^{31}$ In open anterior skull base surgery, compared with preoperative levels, ASBQ scores have been found to be predominantly stable (37\%) or improved (37\%) within 3 to 6 months postoperatively, ${ }^{4,5}$ improving markedly in the 6 to 24 months following surgery 4,5 and remaining relatively stable $e^{4}$ or decreasing ${ }^{5}$ thereafter.

Recent prospective data on endoscopic surgery suggest that, compared with preoperative levels, a significant improvement in ASBQ scores is noted as early as the 12-week point. ${ }^{32,33}$ In this endoscopic cohort, the only domain to deteriorate postoperatively was specific symptoms (sinonasal), which was a transient deterioration. In another study, compared with those undergoing open anterior skull base surgery, those undergoing endoscopic approaches had better ASBQ scores in all domains except the specific symptoms domain (where there was a nonsignificant difference). ${ }^{34}$ Further, significantly higher scores in the physical function and impact on emotions domains was observed (even when excluding pituitary tumors). Another study comparing endoscopic and subcranial approaches also suggested similar scores for sinonasal morbidity between the two approaches, suggesting QoL to be more influenced by other factors such as skin incisions, craniotomy, visual function, and psychological issues, all of which predominate in open surgery. ${ }^{34}$

Factors identified as deleterious to ASBQ scores in those undergoing open surgical approaches to anterior skull base tumors include malignant as opposed to benign disease (affecting overall QoL ${ }^{4}$ and the domains of specific symptoms, ${ }^{4,5,34}$ influence on emotions, ${ }^{4,5,34}$ performance, ${ }^{4,5}$ vitality, $^{34}$ and physical function ${ }^{4,5,34}$ ), radiotherapy (specific symptoms $^{4,5,34}$ and influence on emotions $s^{4,5,34}$ domains), old age (performance $e^{5}$ and physical function ${ }^{5,34}$ domains), ${ }^{4}$ female gender (in all domains but specific symptoms), ${ }^{34}$ comorbidity (physical function domain), ${ }^{4}$ the classic as opposed to combined subcranial approach (specific symptoms domain), ${ }^{20}$ and wide resection, ${ }^{4}$ supported in some instances by multivariate analysis. ${ }^{34}$ Primary surgery as opposed to secondary operations, not undergoing nasoseptal flap reconstruction, and the transsellar approach compared with other approaches are all associated with higher ASBQ scores. ${ }^{31}$

However, for those undergoing endoscopic surgery, malignancy, ${ }^{34}$ age, ${ }^{34}$ radiation therapy, ${ }^{34}$ presence of comorbidities, ${ }^{34}$ prior surgery, ${ }^{34}$ type of pathology (pituitary or nonpituitary tumor), ${ }^{32,33}$ secreting versus nonsecreting tumor, ${ }^{32,33}$ anatomical region involved, ${ }^{34}$ use of a nasoseptal flap reconstruction, ${ }^{32,33}$ use of a second surgical donor site, ${ }^{32,33}$ and the presence of postoperative complications do not appear to be associated with postoperative ASBQ score. In a prospective endoscopic cohort, mean preoperative scores were significantly worse in those undergoing revision surgery compared with those undergoing first-time surgery, but this difference was lost postoperatively. ${ }^{32,33}$ Gross total resection was associated with significantly higher scores overall and in all domains at 12 weeks and 6 months after endoscopic surgery. ${ }^{32,33}$

In comparing patient, caregiver, and surgeon ratings of a patient's QoL, ASBQ scores at the group level had good correlations between mean scores reported by patients and their caregivers. ${ }^{6}$ Only in the specific symptoms domain did caregivers significantly overrate patient scores. Within individual patient-caregiver pairs, there was an overall significant agreement between patients' and caregivers' perceptions of QoL and significant agreement in all domains except the effect of emotions domain (minor correlation) and pain (no correlation). Correlations were strong for patients who had recurrent and not primary disease. In most cases the surgeon overestimated overall QoL scores in their patients, with no significant correlations between the patients' and surgeons' scores at the individual level.

Methodological limitations of studies reporting ASBQ scores include subjects retrospectively assessing preoperative 


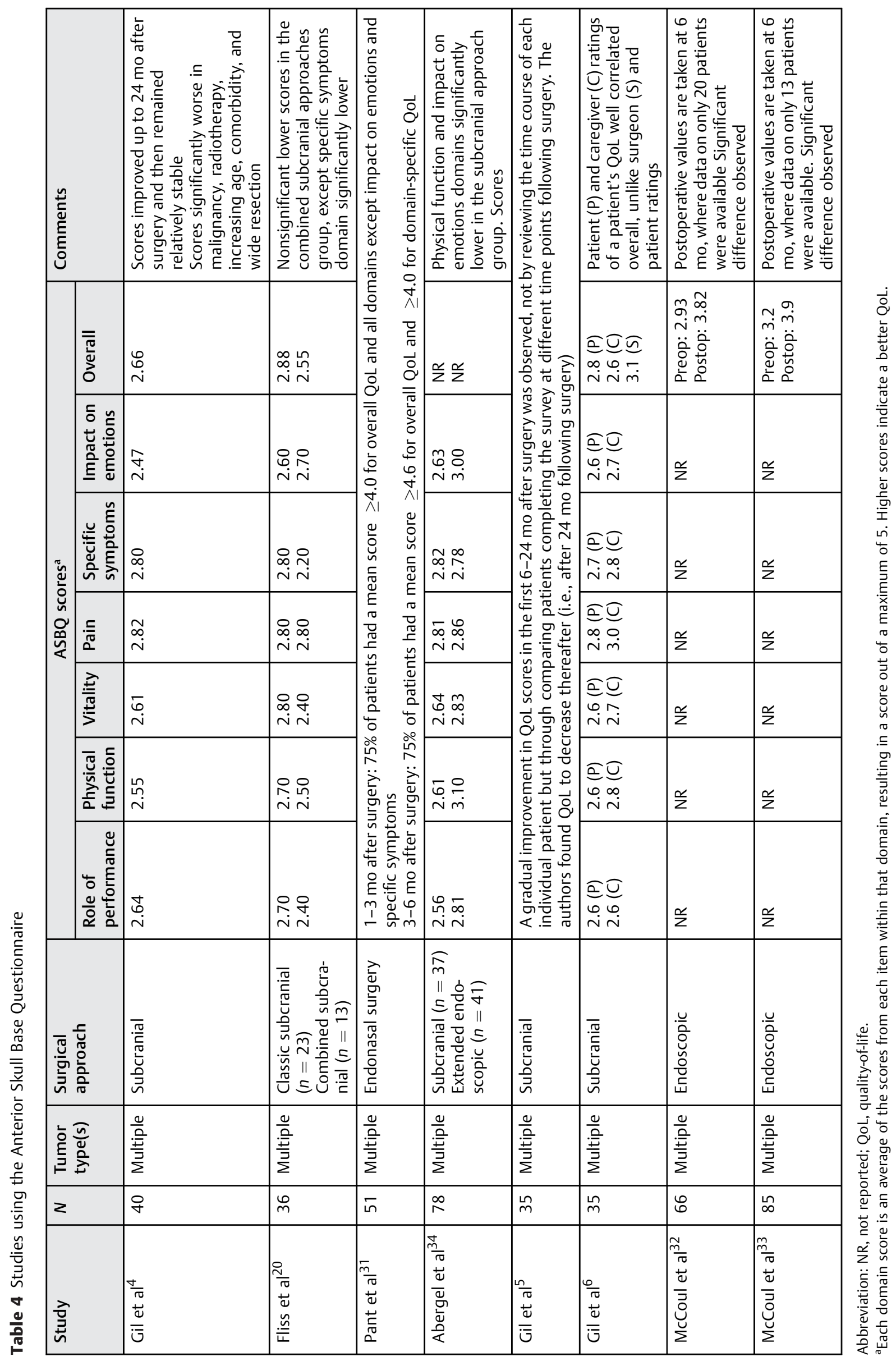


QoL in the setting of prospective postoperative data, ${ }^{4}$ not specifying the specific types and locations of skull base tumors included, ${ }^{31}$ not reporting mean length of followup, $^{31}$ or not providing preoperative data for comparison. ${ }^{20,31,34}$ Small sample sizes were present in some studies at later time points. ${ }^{32,33}$ The inclusion of predominantly benign pathology may limit the generalizability of findings in some studies ${ }^{32,33}$ (although one may consider the wide heterogeneity of pathologies included in some studies equally deleterious).

\section{Sinonasal Outcome Test-22}

The Sinonasal Outcome Test (SNOT)-22 is a 22-item selfreporting questionnaire originally designed for the assessment of QoL related to benign sinonasal disease. Each item is a specific symptom that the patient rates from 0 (no problem) to 5 (as bad as it can be), depending on how much (severity and frequency) each symptom troubles the patient. In this regard, it is not tailored for patients undergoing skull base surgery because it assesses for ear-related symptoms and sneezing but not for symptoms such as sense of smell and taste, nasal crusting, and nasal whistling that are especially relevant for endonasal skull base surgery. Nevertheless, use of the SNOT-22 has shown improvement in sinonasal morbidity following surgery in five studies of skull base surgery patients. $^{23,31-33}$

Mean SNOT-22 scores in 51 patients undergoing endonasal surgery for skull base tumors were significantly higher 6 to 12 months after surgery compared with in the first 3 months. ${ }^{31}$ Significantly better scores were seen in those undergoing the transsellar approach as opposed to other approaches, and those not having nasoseptal flap reconstruction. The five most common items reported as the most important influences on health were loss of smell or taste, nasal obstruction, postnasal discharge, waking up at night, and lack of a good night's sleep. Approximately a quarter of patients indicated a severe problem relating to loss of smell or taste. However, in this study the specific types of skull base tumor and location were not specified; neither was the mean length of follow-up.

A further study of 11 patients undergoing endoscopic skull base surgery for a range of benign and malignant skull base tumors found SNOT-22 scores to improve significantly postoperatively within subjects, from a mean of 47 preoperatively to 14 postoperatively. ${ }^{23}$ Although data was collected 3, 6, and 12 points postoperatively, no temporal patterns in scores were described.

A prospective series of patients with pituitary and other anterior skull base tumors undergoing endoscopic surgery found SNOT-22 scores to be higher (worse) 3 weeks after surgery compared with preoperatively, but scores at the 6week, 12-week, and 6-month points did not differ from preoperative scores. ${ }^{32,33}$ At the 12 -month point, however, SNOT-22 scores were significantly improved from preoperative scores. ${ }^{33}$ A significantly inverse correlation was seen between SNOT-22 and ASBQ scores at all time points (which was expected, given that higher ASBQ scores and lower SNOT-22 scores are both favorable), ${ }^{33}$ and also be- tween SNOT-22 scores and the specific symptoms domain of ASBQ. ${ }^{32}$ Mean preoperative SNOT-22 scores were significantly worse for those undergoing revision surgery as opposed to primary surgery, but this difference was lost postoperatively. Gross total resection was associated with improved SNOT-22 scores and individual domain scores at 6 months and 12 months. Further, use of autologous tissue transfer from a second operative site was associated with better mean SNOT-22 scores at 12 weeks, 6 months, and 12 months postoperatively. No significant differences in mean SNOT-22 values were found when comparing pituitary and nonpituitary pathology, functional and nonfunctional tumor, use of a nasoseptal flap or gasket seal reconstruction, or the occurrence of an intraoperative cerebrospinal fluid (CSF) leak.

An abbreviated 8-item version of the SNOT-22 was recently administered to 22 patients undergoing endoscopic transsphenoidal skull base surgery for pituitary adenomas and Rathke cleft cysts. ${ }^{35}$ After a mean of 58 days following surgery, no difference in pre- and postoperative scores was observed, olfactory function (as assessed by the University of Pennsylvania Smell Identification Test) was preserved, but a slight worsening of objective endoscopic appearance (using the Lund-Kennedy Endoscopic Scoring system) was also noted. However, this was probably too early a follow-up for any meaningful conclusions to be drawn about sinonasal and olfactory outcomes.

\section{Rhinosinusitis Outcome Measure-31}

The Rhinosinusitis Outcome Measure (RSOM)-31 is a larger and more complex questionnaire than its more condensed offspring, the SNOT-22. This 31-item questionnaire has been used in a study of 91 patients undergoing either endoscopic transsphenoidal surgery (mean follow-up: 1104 days) or extended endonasal approaches (142 days) to a variety of skull base tumors, where no overall difference in scores between the two groups was found. ${ }^{36}$ However, sense of smell and headache were significantly worse in those undergoing nasoseptal flap reconstruction but did improve with time. The presence of a hormone-secreting adenoma was associated with a significantly worse RSOM-31 score.

\section{Anterior Skull Base Nasal Inventory-9}

The Anterior Skull Base (ASK) Nasal Inventory-9 is a selfreporting QoL survey for assessing nasal outcomes following endonasal pituitary and skull base surgery. It is composed of a nine-question patient survey focusing on the most common postoperative complains including crusting, sinusitis, pain, and ease of breathing but as such is unidimensional. Questions determine how often patients experience specific symptoms, with scores ranging from 1 (never) to 5 (all of the time). The ASK Nasal Inventory- 9 has been prospectively validated in 94 patients undergoing endonasal surgery for pituitary tumors, anterior skull base tumors, and endoscopic repair of CSF leaks $(n=52)$, in addition to a control group consisting of patients undergoing nonendonasal neurosurgical procedures $(n=42) .{ }^{37}$ Administered before and 3 months after surgery, it found that most patients have good, very good, or excellent 
self-rated nasal function at 3 months, although comparisons with preoperative ratings were not presented.

\section{Anterior Skull Base Nasal Inventory-12}

Subsequent refinement of the ASK Nasal Inventory-9 as described in a recent article has resulted in a new 12-item tool, incorporating expansion of the 5-point to a 6-point rating scale to improve the discrimination of mild to moderate symptoms. ${ }^{38}$ Furthermore, the rating scale of the ASK Nasal Inventory-12 is based on symptom severity as opposed to frequency (as in ASK Nasal Inventory-9). In a study of 104 patients undergoing endonasal skull base surgery for a range of sellar pathologies, sensory, nasal obstruction, and nasal discharge symptoms deteriorated the most within the first 2 to 4 weeks of surgery compared with preoperatively. ${ }^{38}$ Dizziness, ear pain, nosebleeds, and eye tearing showed no significant change following surgery, and the symptoms ranked most important by patients were sense of smell, headache, and symptoms of nasal obstruction. Symptoms reported as least important to patients included nose whistling, teeth and ear pain, nose bleeds, and the sound quality of voice.

The ASK Nasal Inventory-12 was found to be a valid and reliable tool and is currently being evaluated in a multicenter nasal outcomes study (Rhinological Outcomes in Endonasal Pituitary Surgery, ClinicalTrials.gov identifier NCT01504399).

\section{Midface Dysfunction Scale}

The Midface Dysfunction Scale (MDS) is a four-item questionnaire covering visual, olfactory, taste, and nasal symptoms, with scores for each of the items ranging from 0 (not at all) to 4 (very much), generating a maximum possible score of 16 . The MDS has been used in a study of 27 patients undergoing cranial, transfacial, and craniofacial approaches to a variety of benign and malignant skull base tumors where the FACTH\&N, CES-D, and ALHR were used (as previously described). ${ }^{30}$ The median MDS score was 8 (minimum postoperative follow-up: 6 months; median: 5 years), with most patients reporting significant disturbance of smell and nasal crusting. Higher MDS scores $(\geq 8)$ were associated with a significant reduction in the total FACT $\mathrm{H} \& \mathrm{~N}$ score and an increase in the CES-D score, compared with those scoring $<8$. However, the brevity of MDS limits its utility as a stand-alone QoL measure.

\section{Discussion}

Here we present the first systematic review assessing QoL following anterior skull base surgery. Despite the limitations and heterogeneity in study design, populations, and outcome measures used, several key messages can be derived from our data. The first finding is that, following anterior skull base surgery in adults in the modern era, QoL tends to improve beyond preoperative levels in the months following surgery. For patients undergoing endoscopic surgery, the benefits in QoL may be more significant and manifest earlier, with no clear long-term deleterious effect on sinonasal outcomes compared with open surgery. Several factors appear to influence QoL in patients undergoing anterior skull base surgery, and these influences depend on whether open or endoscopic approaches are used. The temporal changes in QoL generally observed following skull base surgery may be, at least in part, due to the patient adjusting to his or her condition.

A contentious area of debate is whether endoscopic or open anterior skull base surgery offers the best QoL for the patient. As noted earlier, improvements in QoL seem to appear earlier in the endoscopic group. ASBS scores have been found to be generally higher in those undergoing endoscopic surgery. ${ }^{4,31,34}$ Such comparisons, however, are complicated by the heterogeneity of the two populations, the different indications for surgical intervention, the varying proportions of malignant tumors included in studies, and the differences in rates of radiotherapy as well as the varying extents of surgical resection achieved by the two approaches. A decision analysis study comparing endoscopic with open resection of tuberculum sellae meningiomas found no significant overall difference in QoL between the two surgical approaches. ${ }^{39}$ However, there were significant differences in specific complications associated with reductions in QoL; open approaches appeared to have a higher risk of visual loss, whereas endoscopic approaches had a higher risk of CSF leakage and pituitary dysfunction.

QoL is not a unidimensional concept, and its measurement should ideally encompass physical, social, psychological, and functional domains. ${ }^{40}$ In skull base surgery patients, important facets in addition to functional status include pain control, social well-being, cognitive symptoms, emotional health, and physical and aesthetic appearance. ${ }^{41}$ Several of the tools used in skull base surgery as reported here lack multidimensional assessment of QoL and are not site specific. Although some of these generic tools are well established, have validity and reliability, and permit comparisons across different diseases, interventions, and population groups, ${ }^{42}$ they do not necessarily detect the changing clinical status of a skull base tumor patient and, by their very nature, they often fail to account for specific outcomes deemed important for this specific population group. Disease- and site-specific QoL scales are responsive to clinical changes and thus perceived as more clinically relevant, and they are especially useful for clinical trials where specific interventions are being evaluated, ${ }^{43}$ but they are not as useful for health economic analysis and comparisons between diseases.

The potential benefits of using QoL tools routinely in clinical practice are clear. They may help provide individualized patient care by identifying specific patient needs, aid in appropriately targeted treatment of individuals with specific QoL features that make them at a higher risk of poor outcome, and, through patients accessing their own predicted QoL status, allow them to better adjust to their morbidity. ${ }^{44}$

Despite these benefits, the acquisition of QoL data in the skull base tumor population is not straightforward; most patients are elderly with multiple comorbidities, many have a short life expectancy that makes data collection and followup difficult, and the small numbers of patients and histologic variability of the lesions makes meaningful conclusions difficult to interpret. ${ }^{45}$ Calculation of the minimal clinically important difference (MCID), defined as the smallest change in QoL perceived by patients as beneficial, is one way in which 
the clinical relevance of small but statistically significant changes in QoL can be ascertained. ${ }^{45}$ Use of MCID may help, for example, in establishing the superiority of one surgical approach to another, and it has been demonstrated in a study using ASBQ. ${ }^{34}$ Any change in QoL will depend on preoperative clinical status. Deteriorating postoperative QoL scores may be expected if the patient was asymptomatic prior to treatment. ${ }^{4}$ This leads to the important concept that $\mathrm{QoL}$ surveys do not account for the fact that many skull base tumor patients undergo surgery to prevent further problems rather than treat present symptoms. Patients may also report a poor QoL despite a seemingly successful operation; reasons for this may be multifactorial and must be addressed at the individual level.

This leads naturally to the question of who is the best judge of a patient's QoL. We have presented data suggesting good overall agreement between patient ratings and those of their caregivers, although caregivers tend to overrate the presence of specific symptoms. ${ }^{6}$ Recurrent disease appears to improve the agreement between patient and caregiver. ${ }^{6,46}$ In comparison, agreement between patient and surgeon is poor. ${ }^{6}$ In some instances a proxy measure of $\mathrm{QoL}$ (e.g., from a caregiver) may be necessary, such as in the case of children or patients lacking capacity; however, rating agreements can decrease as patients' physical and cognitive status declines, questioning the role of proxy ratings for those who may need them most. ${ }^{47}$

We have gained much from the last decade of research into QoL in skull base patients. Historically, clinical studies in skull base surgery focused on surgical approaches, complications, and mortality rates, and early measurements of QoL were based on the Karnofsky score. As highlighted earlier, we now have a much better awareness and understanding of the importance for the patient of QoL following skull base surgery, an understanding of the temporal trends in postoperative QoL, an appreciation of the importance of multidimensional QoL assessment, and of the need to obtain QoL data from the patient and not the surgeon where possible. We now realize that an essential goal of anterior skull base tumor treatment is restoration of QoL and not improvement in survival alone, important given the often invasive nature of the surgery (plus adjuvant therapies) involved. So important is the measurement of a patient's QoL that preoperative QoL measures may predict postoperative $\mathrm{QoL}^{20}$ and even survival. $^{48,49}$

What can the clinician do to help optimize the QoL of patients with anterior skull base tumors? First, a surgeon must understand the different aspects that constitute a patient's QoL. Regular follow-up with administration of multidimensional QoL questionnaires in patients with skull base tumors would help facilitate this. The aim would be to improve the evaluation and management of these patients, identifying patient-specific deficits and needs early, and ensuring the deployment of appropriate targeted interventions in those who need it most. ${ }^{44}$ Risk factors for poor QoL in this setting include malignancy, recurrence, comorbidities, and increasing age. Access to comprehensive information about their own predicted QoL may also help the patient adjust to his or her own morbidity.
Adequate pain control is essential because skull base surgery is associated with significant pain in the early postoperative stages. Despite a plethora of analgesic preparations, which types and combinations are best in this setting remains controversial. ${ }^{50}$ Use of a multidisciplinary health care team and access to a community support network would also help ensure that all patient needs, including psychosocial, are met. ${ }^{51}$ of utmost importance, the surgeon must appreciate that he or she cannot fully appreciate a patient's QoL without asking them.

Where does the future lie for studies of QoL in anterior skull base surgery? To fully understand the QoL in patients undergoing anterior skull base surgery, the relative paucity and heterogeneity of these tumors necessitates the conduction of large-scale multicenter prospective studies. This could be done with the aid of an Internet database ${ }^{52}$ and has proven to be possible when assessing oncologic outcomes for patients with anterior skull base tumors. ${ }^{53}$ Long-term follow-up data and standardization of outcome measures is necessary. This information will provide valuable insight into the concerns facing patients with skull base tumors, allow comparison of treatments, and inform future treatment decisions.

\section{Conclusions}

QoL following anterior skull base surgery in adults improves in the months after the operation. For patients undergoing endoscopic skull base surgery, the QoL gains appear to be greater and may manifest earlier, with no clear long-term deleterious effects on sinonasal outcomes over open surgery. Studies assessing QoL in this population to date are confounded by varying populations, methodological quality, and follow-up periods.

Improved treatment and survival rates among patients with skull base tumors have made the assessment of QoL in this population increasingly important. Assessing functional status alone, however, is not enough. Given the relative paucity and heterogeneity of anterior skull base tumors, large-scale prospective multicenter studies utilizing QoL tools (such as the ASBQ) that have established reliability and validity are required. The tools should be completed by the patient or caregiver, rather than the clinician. The outcome should be improved patient care, through better understanding our patients' needs and facilitating the provision of robust outcome data for clinical trials.

\section{Funding Source}

This work was performed at UCL/UCLH Biomedical Research Centre, which receives funding from the National Institute for Health Research (NIHR), UK. Matthew A. Kirkman is an NIHR Academic Clinical Fellow in Neurosurgery. David Choi receives funding from the European Research Council.

\section{References}

1 Witgert ME, Veramonti T, Hanna E. Instruments for estimation of health-related quality of life in patients with skull base neoplasms. Skull Base 2010;20(1):5-10 
2 Murphy BA, Ridner S, Wells N, Dietrich M. Quality of life research in head and neck cancer: a review of the current state of the science. Crit Rev Oncol Hematol 2007;62(3):251-267

3 Karnofsky DA, Burchenal JH. Present status of clinical cancer chemotherapy. Am J Med 1950;8(6):767-788

4 Gil Z, Abergel A, Spektor S, et al. Quality of life following surgery for anterior skull base tumors. Arch Otolaryngol Head Neck Surg 2003;129(12):1303-1309

5 Gil Z, Abergel A, Spektor S, Shabtai E, Khafif A, Fliss DM. Development of a cancer-specific anterior skull base quality-of-life questionnaire. J Neurosurg 2004;100(5):813-819

6 Gil Z, Abergel A, Spektor S, Khafif A, Fliss DM. Patient, caregiver, and surgeon perceptions of quality of life following anterior skull base surgery. Arch Otolaryngol Head Neck Surg 2004;130(11):1276-1281

7 Moher D, Liberati A, Tetzlaff J, Altman DG; PRISMA Group. Preferred reporting items for systematic reviews and meta-analyses: the PRISMA statement. PLoS Med 2009;6(7):e1000097

8 Raso JL, Gusmão S. Transbasal approach to skull base tumors: evaluation and proposal of classification. Surg Neurol 2006;65 (Suppl 1):S1, 33-1, 37; discussion 1, 37-1, 38

9 Tzortzidis F, Elahi F, Wright D, Natarajan SK, Sekhar LN. Patient outcome at long-term follow-up after aggressive microsurgical resection of cranial base chordomas. Neurosurgery 2006;59(2): 230-237; discussion 230-237

10 Di Maio S, Rostomily R, Sekhar LN. Current surgical outcomes for cranial base chordomas: cohort study of 95 patients. Neurosurgery 2012;70(6):1355-1360; discussion 1360

11 Bassiouni H, Asgari S, Sandalcioglu IE, Seifert V, Stolke D, Marquardt G. Anterior clinoidal meningiomas: functional outcome after microsurgical resection in a consecutive series of 106 patients. Clinical article. J Neurosurg 2009;111(5):1078-1090

12 Ichinose T, Goto T, Ishibashi K, Takami T, Ohata K. The role of radical microsurgical resection in multimodal treatment for skull base meningioma. J Neurosurg 2010;113(5):1072-1078

13 Roser F, Ebner FH, Ritz R, Samii M, Tatagiba MS, Nakamura M. Management of skull based meningiomas in the elderly patient. J Clin Neurosci 2007;14(3):224-228

14 de Almeida JR, Witterick IJ, Gullane PJ, et al. Physical morbidity by surgical approach and tumor location in skull base surgery. Head Neck 2013;35(4):493-499

15 Holmes B, Sekhar L, Sofaer S, Holmes KL, Wright DC. Outcomes analysis in cranial base surgery-preliminary results. Acta Neurochir (Wien) 1995;134(3-4):136-138

16 Ohba S, Kobayashi M, Horiguchi T, et al. Long-term surgical outcome and biological prognostic factors in patients with skull base meningiomas. J Neurosurg 2011;114(5):1278-1287

17 De Jesús O, Sekhar LN, Parikh HK, Wright DC, Wagner DP. Longterm follow-up of patients with meningiomas involving the cavernous sinus: recurrence, progression, and quality of life. Neurosurgery 1996;39(5):915-919; discussion 919-920

18 Samii A, Gerganov V, Herold C, Gharabaghi A, Hayashi N, Samii M. Surgical treatment of skull base chondrosarcomas. Neurosurg Rev 2009;32(1):67-75; discussion 75

19 Walch C, Stammberger H, Anderhuber W, Unger F, Köle W, Feichtinger $\mathrm{K}$. The minimally invasive approach to olfactory neuroblastoma: combined endoscopic and stereotactic treatment. Laryngoscope 2000;110(4):635-640

20 Fliss DM, Abergel A, Cavel O, Margalit N, Gil Z. Combined subcranial approaches for excision of complex anterior skull base tumors. Arch Otolaryngol Head Neck Surg 2007;133(9):888-896

21 Bassiouni H, Asgari S, Stolke D. Olfactory groove meningiomas: functional outcome in a series treated microsurgically. Acta Neurochir (Wien) 2007;149(2):109-121; discussion 121

22 Lang DA, Honeybul S, Neil-Dwyer G, Evans BT, Weller RO, Gill J. The extended transbasal approach: clinical applications and complications. Acta Neurochir (Wien) 1999;141(6):579-585

23 Ransom ER, Doghramji L, Palmer JN, Chiu AG. Global and diseasespecific health-related quality of life after complete endoscopic resection of anterior skull base neoplasms. Am J Rhinol Allergy 2012;26(1):76-79

24 Rogers SN, Gwanne S, Lowe D, Humphris G, Yueh B, Weymuller EA Jr. The addition of mood and anxiety domains to the University of Washington quality of life scale. Head Neck 2002;24(6):521-529

25 Hassan SJ, Weymuller EA Jr. Assessment of quality of life in head and neck cancer patients. Head Neck 1993;15(6):485-496

26 Martinez-Devesa P, Barnes ML, Alcock CJ, Kerr RS, Milford CA. Evaluation of quality of life and psychiatric morbidity in patients with malignant tumours of the skull base. J Laryngol Otol 2006; 120(12):1049-1054

27 Jennett B, Bond M. Assessment of outcome after severe brain damage. Lancet 1975;1(7905):480-484

28 Blau T. Quality of life, social indicators, and criteria of change. Prof Psychol 1977;11:464-473

29 Woertgen C, Rothoerl RD, Hosemann W, Strutz J. Quality of life following surgery for malignancies of the anterior skull base. Skull Base 2007;17(2):119-123

30 Palme CE, Irish JC, Gullane PJ, Katz MR, Devins GM, Bachar G. Quality of life analysis in patients with anterior skull base neoplasms. Head Neck 2009;31(10):1326-1334

31 Pant H, Bhatki AM, Snyderman CH, et al. Quality of life following endonasal skull base surgery. Skull Base 2010;20(1):35-40

32 McCoul ED, Anand VK, Schwartz TH. Improvements in site-specific quality of life 6 months after endoscopic anterior skull base surgery: a prospective study. J Neurosurg 2012;117(3):498-506

33 McCoul ED, Anand VK, Bedrosian JC, Schwartz TH. Endoscopic skull base surgery and its impact on sinonasal-related quality of life. Int Forum Allergy Rhinol 2012;2(2):174-181

34 Abergel A, Cavel O, Margalit N, Fliss DM, Gil Z. Comparison of quality of life after transnasal endoscopic vs open skull base tumor resection. Arch Otolaryngol Head Neck Surg 2012;138(2):142-147

35 Sowerby LJ, Gross M, Broad R, Wright ED. Olfactory and sinonasal outcomes in endoscopic transsphenoidal skull-base surgery. Int Forum Allergy Rhinol 2013;3(3):217-220

36 Georgalas C, Badloe R, van Furth W, Reinartz S, Fokkens WJ. Quality of life in extended endonasal approaches for skull base tumours. Rhinology 2012;50(3):255-261

37 Little AS, Jahnke H, Nakaji P, Milligan J, Chapple K, White WL. The anterior skull base nasal inventory (ASK nasal inventory): a clinical tool for evaluating rhinological outcomes after endonasal surgery for pituitary and cranial base lesions. Pituitary 2012;15(4): 513-517

38 Little AS, Kelly D, Milligan J, et al. Prospective validation of a patient-reported nasal quality-of-life tool for endonasal skull base surgery: The Anterior Skull Base Nasal Inventory-12. J Neurosurg 2013;119(4):1068-1074

39 Bohman LE, Stein SC, Newman JG, et al. Endoscopic versus open resection of tuberculum sellae meningiomas: a decision analysis. ORL J Otorhinolaryngol Relat Spec 2012;74(5):255-263

40 Mohsenipour I, Deusch E, Gabl M, Hofer M, Twerdy K. Quality of life in patients after meningioma resection. Acta Neurochir (Wien) 2001;143(6):547-553

41 Shah JP. Quality of life after skull base surgery: the patient's predicament. Skull Base 2010;20(1):3-4

42 DeMonte F. Functional outcomes in skull base surgery. What is acceptable? Clin Neurosurg 2001;48:340-350

43 Levine NB, Demonte F. Functional outcome in the neurosurgical patient and its impact on quality of life. Skull Base 2010;20(1):19-22

44 Gil Z. Quality of life in patients with skull base tumors. Skull Base 2010;20(1):1

45 Amit M, Abergel A, Fliss DM, Gil Z. The clinical importance of quality-of-life scores in patients with skull base tumors: a metaanalysis and review of the literature. Curr Oncol Rep 2012;14(2): 175-181

46 Deschler DG, Walsh KA, Friedman S, Hayden RE. Quality of life assessment in patients undergoing head and neck surgery as evaluated by lay caregivers. Laryngoscope 1999;109(1):42-46 
47 Sneeuw KC, Aaronson NK, Osoba D, et al. The use of significant others as proxy raters of the quality of life of patients with brain cancer. Med Care 1997;35(5):490-506

48 Movsas B. Exploring the role of the radioprotector amifostine in locally advanced non-small cell lung cancer: Radiation Therapy Oncology Group trial 98-01. Semin Radiat Oncol 2002;12(1, Suppl 1):40-45

49 Langendijk H, Aaronson NK, de Jong JM, ten Velde GP, Muller MJ, Wouters M. The prognostic impact of quality of life assessed with the EORTC QLQ-C30 in inoperable non-small cell lung carcinoma treated with radiotherapy. Radiother Oncol 2000; 55(1):19-25
50 Gil Z, Smith DB, Marouani N, Khafif A, Fliss DM. Treatment of pain after head and neck surgeries: control of acute pain after head and neck oncological surgeries. Otolaryngol Head Neck Surg 2006; 135(2):182-188

51 Gil Z, Fliss DM. Quality of life in patients with skull base tumors: current status and future challenges. Skull Base 2010;20(1):11-18

52 Patel SG. Internet-based multi-institutional clinical research: a new method to conduct and manage quality of life studies. Skull Base 2010;20(1):23-26

53 Patel SG, Singh B, Polluri A, et al. Craniofacial surgery for malignant skull base tumors: report of an international collaborative study. Cancer 2003;98(6):1179-1187 


\begin{tabular}{|c|c|c|c|c|c|c|c|c|c|c|c|c|c|c|c|c|c|c|c|c|c|c|c|}
\hline 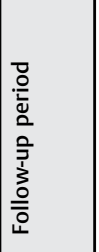 & \begin{tabular}{|l}
$\stackrel{O}{E}$ \\
$m$
\end{tabular} & 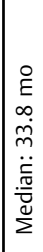 & 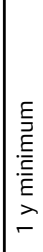 & 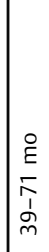 & 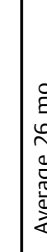 & 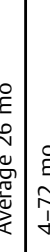 & 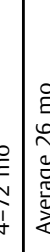 & 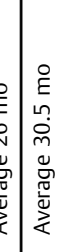 & 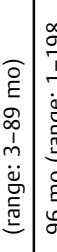 & 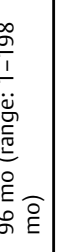 & $\frac{n}{z}$ & 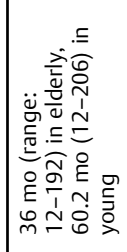 & 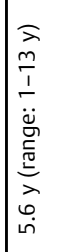 & 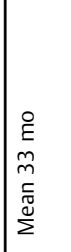 & 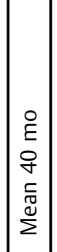 & 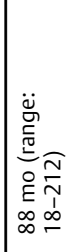 & 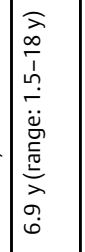 & 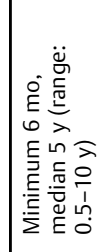 & 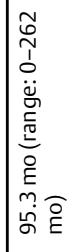 & 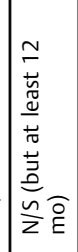 & 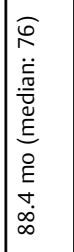 & $\underset{\mathrm{E}}{\stackrel{\circ}{\mathrm{E}}}$ & $\begin{array}{l}\stackrel{0}{E} \\
\stackrel{m}{m} \\
\infty \\
m\end{array}$ \\
\hline 辛 & 2 & i & i & 2 & $\frac{0}{2}$ & $\therefore \mid \frac{1}{2}$ & 2 & $2 \%$ & & $\stackrel{8}{2}$ & $\stackrel{2}{z}$ & 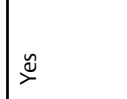 & z & z & $\stackrel{0}{2}$ & i & in & in & in & io & in & 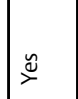 & 2 \\
\hline 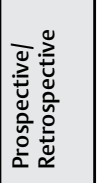 & 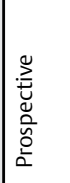 & 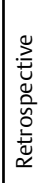 & 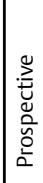 & 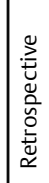 & 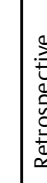 & 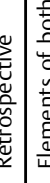 & 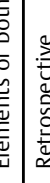 & 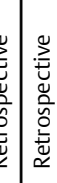 & 列 & 这 & 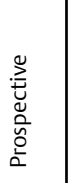 & 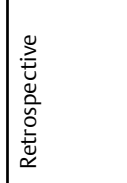 & 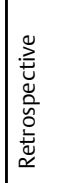 & 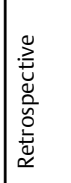 & 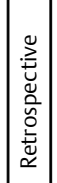 & 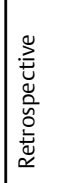 & 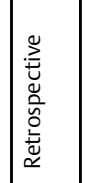 & 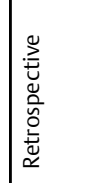 & 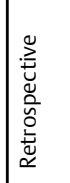 & 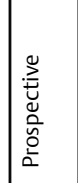 & 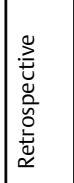 & 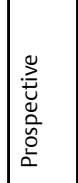 & 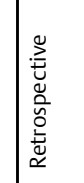 \\
\hline 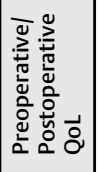 & 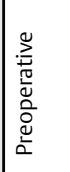 & 产 & 产 & $\frac{n}{z}$ & 表 & $\begin{array}{ll}0 \\
0 \\
c\end{array}$ & 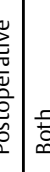 & 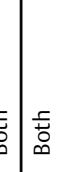 & $\frac{f}{d}$ & 总 & 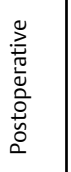 & \begin{tabular}{|l|} 
형 \\
\end{tabular} & 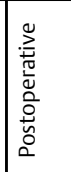 & 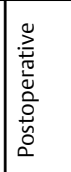 & 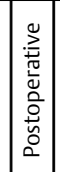 & 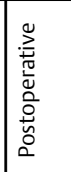 & 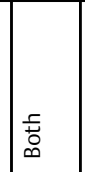 & 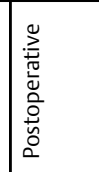 & 言 & 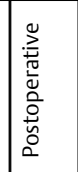 & 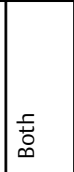 & 言 & 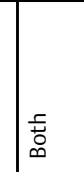 \\
\hline 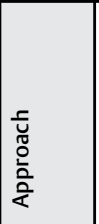 & $\tilde{z}$ & $\tilde{z}$ & 造 & 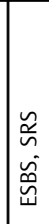 & $v$ & $\checkmark v$ & $\backsim u$ & ئ & 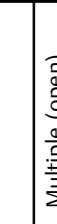 & & 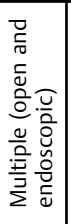 & $\underline{z}$ & 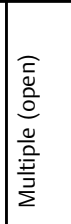 & $u$ & 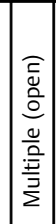 & 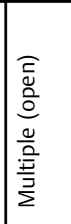 & 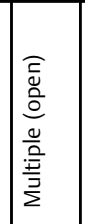 & 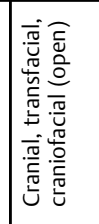 & 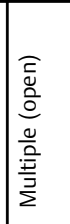 & 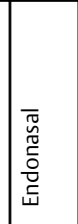 & $n$ & 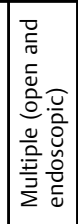 & 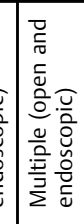 \\
\hline ֻِّ & 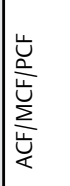 & 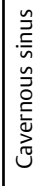 & $\ddot{\psi}$ & 㫕 & 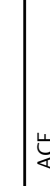 & 宗岁 & $\begin{array}{l}\dot{y} \\
\end{array}$ & t) & 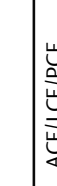 & & 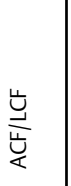 & 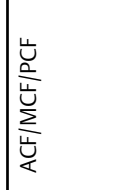 & 岁 & 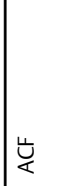 & 岁 & 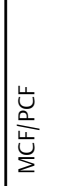 & 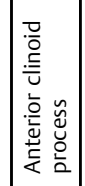 & Uू & 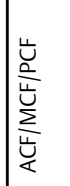 & $\frac{n}{z}$ & 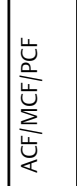 & 岁 & 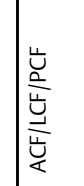 \\
\hline 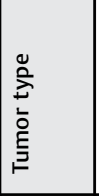 & 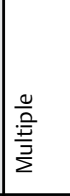 & 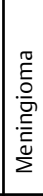 & $\begin{array}{l}\frac{0}{\frac{0}{2}} \\
\frac{\bar{z}}{\overline{2}}\end{array}$ & 訔 & 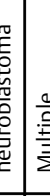 & 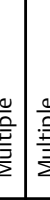 & 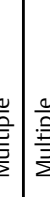 & 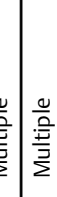 & & 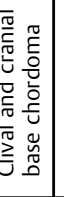 & $\frac{0}{\frac{0}{\underline{\underline{L}}}}$ & 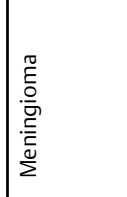 & 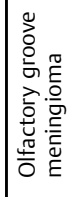 & 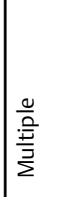 & 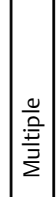 & 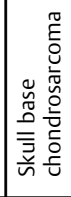 & 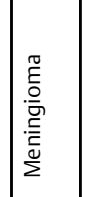 & 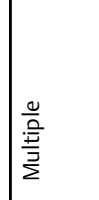 & 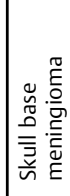 & 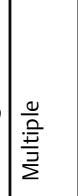 & 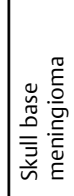 & 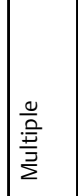 & 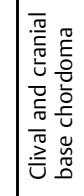 \\
\hline 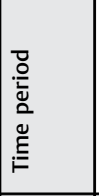 & 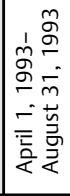 & 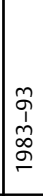 & $\begin{array}{l}\hat{\alpha} \\
\hat{\sigma} \\
\sigma \\
\sigma \\
\underline{\gamma}\end{array}$ & 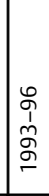 & 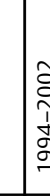 & 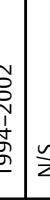 & 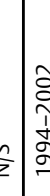 & 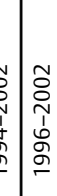 & ટે & & 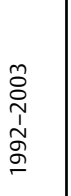 & 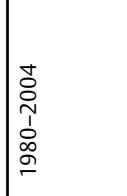 & 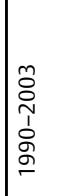 & 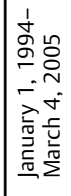 & 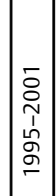 & 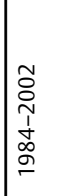 & 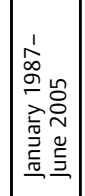 & $\frac{n}{z}$ & 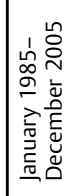 & $\frac{n}{z}$ & 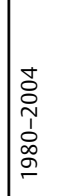 & 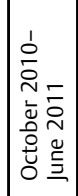 & 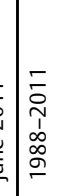 \\
\hline $\begin{array}{l}\overline{8} \\
\stackrel{8}{\circ} \\
\text { 。 }\end{array}$ & $\underline{\tilde{a}}$ & $\tilde{a}$ & 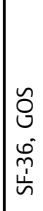 & $\underline{\underline{\underline{y}}}$ & $\begin{array}{l}0 \\
\dot{y} \\
\dot{y} \\
y\end{array}$ & 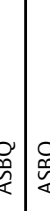 & 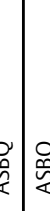 & $\begin{array}{l}0 \\
\vdots \\
\end{array}$ & $\underline{\underline{g}}$ & 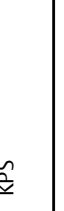 & $\begin{array}{l}\overrightarrow{\mathrm{O}} \\
\text { ذे }\end{array}$ & $\underline{\tilde{\underline{y}}}$ & $\underline{\underline{\underline{x}}}$ & $\begin{array}{l}\hat{\tilde{y}} \\
\underline{0} \\
\tilde{g} \\
\underline{x}\end{array}$ & $\overline{\mathrm{a}}$ & $\underline{\tilde{\underline{y}}}$ & 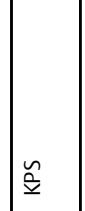 & 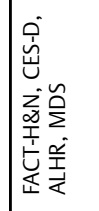 & $\underline{\tilde{y}}$ & 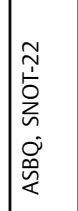 & $\tilde{\tilde{y}}$ & 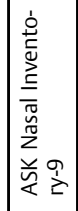 & $\underline{\tilde{y}}$ \\
\hline$z$ & I & $\stackrel{\infty}{=}$ & 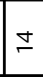 & $m$ & $q$ & \begin{tabular}{l|l}
$g$ \\
$f$
\end{tabular} & $\begin{array}{lll}n & \stackrel{n}{m}\end{array}$ & n & $i$ & \pm & $\stackrel{\infty}{\longleftarrow}$ & $\stackrel{\tilde{m}}{\underline{m}}$ & in & q & $\simeq$ & $\stackrel{\mathscr{N}}{\sim}$ & $\stackrel{\circ}{\circ}$ & $\lesssim$ & 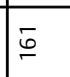 & in & $\stackrel{\infty}{\sim}$ & मे & นू \\
\hline 咅 & 孚 & 孚 & 兰 & 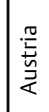 & \begin{tabular}{|l} 
\\
0 \\
$\frac{\pi}{5}$
\end{tabular} & $\begin{array}{l}\overline{\mathbb{v}} \\
\bar{v} \\
\bar{v}\end{array}$ & 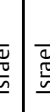 & 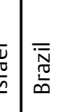 & 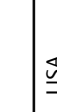 & 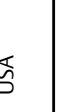 & 兰 & 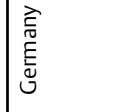 & 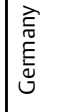 & \begin{tabular}{|l|}
$\overline{\widetilde{w}}$ \\
$\underline{\underline{\underline{w}}}$
\end{tabular} & 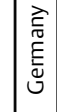 & 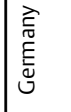 & 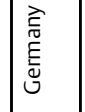 & 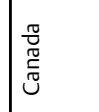 & \begin{tabular}{|l} 
들 \\
足 \\
$\underline{\underline{0}}$
\end{tabular} & 刹 & \begin{tabular}{|l} 
竞 \\
㒸
\end{tabular} & 离 & 芯 \\
\hline 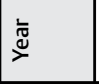 & 喏 & $\begin{array}{l}\stackrel{\circ}{\circ} \\
\sigma \\
-1\end{array}$ & g. & ঃ̊ & 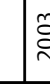 & 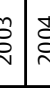 & 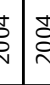 & $\begin{array}{l}\text { s. } \\
\text { s. }\end{array}$ & 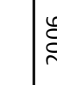 & : & ¿্ণ & 产 & 商 & 䍏 & 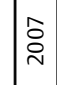 & ஓे̀ & ঐे & O্ণ & 产 & $\stackrel{\circ}{\grave{2}}$ & $\overline{\grave{\alpha}}$ & $\stackrel{\sim}{\stackrel{\sim}{\sim}}$ & 竝 \\
\hline 列 & 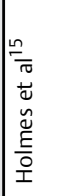 & 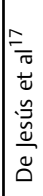 & 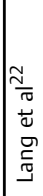 & $\mid \begin{array}{l}\frac{0}{70} \\
\frac{1}{0} \\
\frac{5}{\frac{5}{\pi 0}} \\
\frac{3}{3}\end{array}$ & $\begin{array}{l}\frac{4}{\pi} \\
\frac{\pi}{d} \\
\frac{\pi}{3}\end{array}$ & 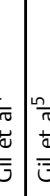 & $\begin{array}{l}\frac{1}{0} \\
\frac{0}{5} \\
5\end{array}$ & 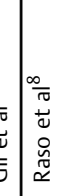 & 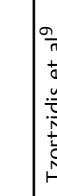 & 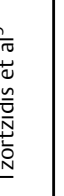 & 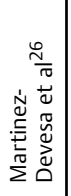 & 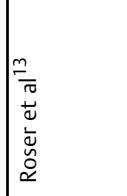 & 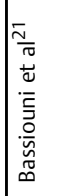 & 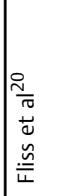 & 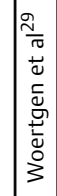 & 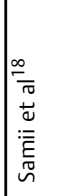 & 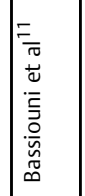 & 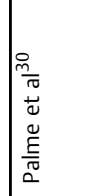 & 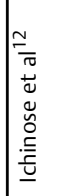 & 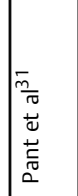 & $\mid \begin{array}{l}\frac{0}{\pi} \\
\frac{\pi}{0} \\
\tilde{0} \\
\tilde{0} \\
\frac{0}{0} \\
0\end{array}$ & 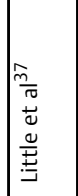 & 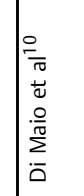 \\
\hline
\end{tabular}




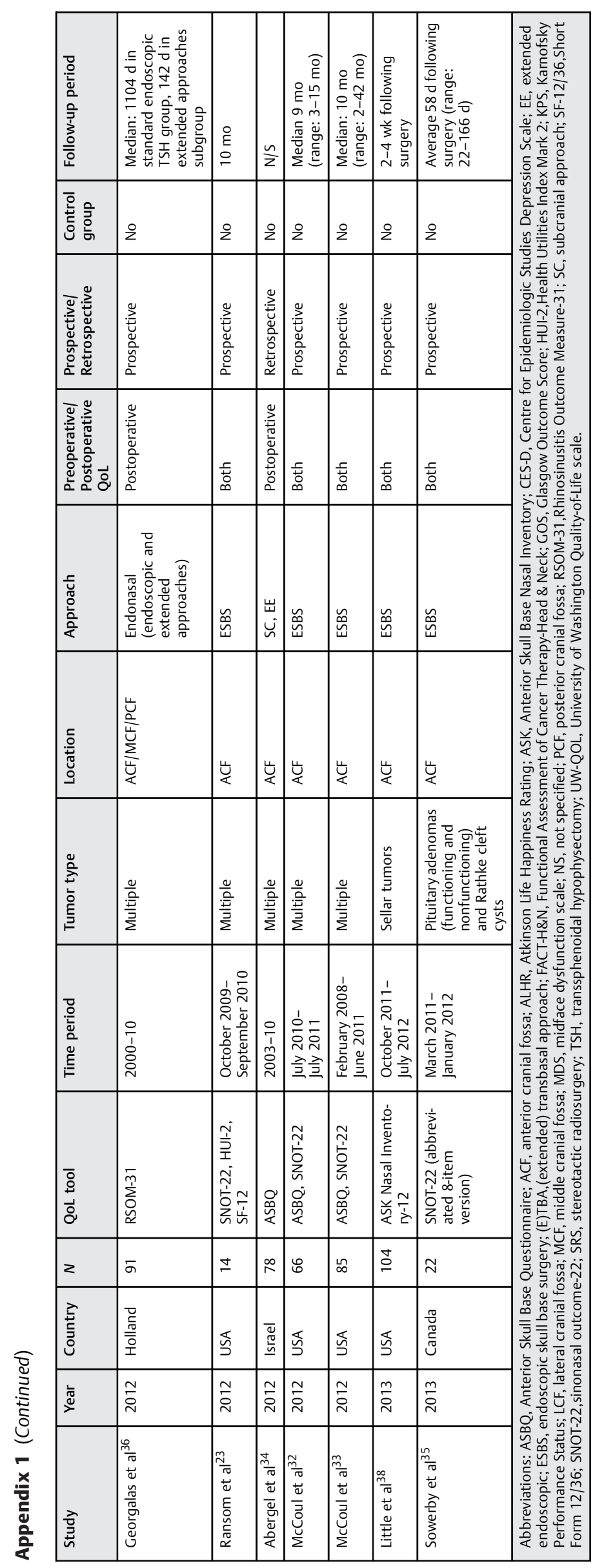

